\title{
Is Psychiatry Ready to Move?
}

\author{
Thibault Deschamps $\bowtie$ \\ Laboratory "Movement, Interactions, Performance" (E.A. 4334), University of Nantes, Nantes, France
}

The following viewpoint about the importance of human movement sciences in mental health is to increase the awareness of the link between motor function or body movement and scientific psychiatry. Clearly, future research approaches should view different bio-psycho-social research areas as complementary rather than competing. With this in mind, I support Cohen's recent call to arms for psychiatrists to foster our understanding of complexity in psychiatric diagnosis, treatment and research. ${ }^{1}$ Like the neurosciences into clinical psychiatry, each scientific field must be cared for, as the basis for patient-centered care. ${ }^{2}$ I argue that mobility and mood disorders must be seen as a unified clinical research entity rather than separate issues. The inherently pluralist activity of psychiatrists provides the first evidence, if not the best, of required interdisciplinary view.

Is psychiatry ready to move? Pardon the pun, this question is intended to be as amusing as a driving force behind solving future challenges as presented herein. Because human movement disorders and psychiatry disorders are complex phenomena, ${ }^{1,3}$ I hope that the readers intrigued by more holistic approaches will perceive this "still frame" as exciting as I think it is. For example, addressing the issue of typical motor hallmarks as possible moderators of effective treatment outcomes in psychiatric disorders ${ }^{4}$ might be a significant step towards collaborative research studies, for the good of psychiatric patients who will benefit such collaboration directly.

Robust evidence shows that motor control and mood disorders are intertwined. ${ }^{5}$ The prevalence of significant depressive symptoms in neurological movement disorders, such as

Received: August 23, 2017 Revised: November 20, 2017

Accepted: December 11, 2017 Available online: January 16, 2018

$\triangle$ Correspondence: Thibault Deschamps, PhD, HDR

Laboratory "Movement, Interactions, Performance" (E.A. 4334), University of Nantes, 25 bis boulevard Guy Mollet, BP 72206, 44322 Nantes Cedex 3, France

Tel: +33 (0)2 518372 14, E-mail: thibault.deschamps@univ-nantes.fr

(a) This is an Open Access article distributed under the terms of the Creative Commons Attribution Non-Commercial License (http://creativecommons.org/licenses/bync/4.0) which permits unrestricted non-commercial use, distribution, and reproduction in any medium, provided the original work is properly cited.
Parkinson's disease, is substantial; ${ }^{6}$ Conversely, depressed patients show alterations in motor function, such as poverty of movement, lower gait or higher postural instability, compared to cognitively normal adults. ${ }^{7}$

The need for better understanding of the role of motor systems in psychopathology is nothing new. Motor function plays a key role in the regulation of psychiatric illness, starting with the physical ability to adapt to everyday life environment, and the prevention and treatment of several mood disorders. An increasing number of studies suggest that physical activity, referring to body movement that leads to energy expenditure, has beneficial effects in people with major depressive disorder (i.e. symptom reduction), ${ }^{8}$ even though half of the people with depression do not experience significant improvements from exercise (remission rates ranging only from $11 \%$ to $41 \%$, as a function of dose response). ${ }^{9}$ Exercise has the potential to improve treatment outcomes in the mental health; ${ }^{10}$ thus, we should continue to promote increased physical activity, but specific clinical, social and biological moderators that predict response to exercise require further validation before a clinical use.

Beyond enhancing our understanding of the neurobiological mechanisms of physical exercise in psychiatric disorders, ${ }^{11}$ considering physical activity as a core set of mental health issues, including its positive effects on self-esteem, quality of life and cognitive functioning, has a holistic value. Regarding cognitive functioning, physical activity has been found to have larger beneficial effect on cognitive task performance among (un)healthy people (young, older, sedentary, addiction, depression...) who received exercise interventions compared to those in control groups. ${ }^{12}$ All else being equal, changes in executive function may facilitate the adoption of health behaviors (sleep, healthy diet, substance use... and physical activity). For example, more efficient exercise-related executive functioning is likely to increase the individual's ability to resist temptation and act impulsively, to turn his/her intentions into actual scheduled actions, and to control his/her at- 
tention, behaviour, (intrusive) thoughts, and/or emotions. Regardless of whether physical activity precedes or follows the executive function, recent research evidence on this virtuous circular causality is mounting. I see no reason for the mental disorders to not fit into this model, and benefit from the exercise-related bio-psycho-social health behaviour model, whether for the prevention and the treatment.

Another challenge that must be addressed concerns the identification of motor signatures/symptoms that may guide psychiatric diagnosis and the treatment decision. ${ }^{13}$ In clinical psychiatry, among other field, mood, cognitive and movement disorders co-occur frequently, and the presence of either disorder is likely to increase the risk of the other. Supported by a chronological relationship, a poor gait performance (e.g. low gait speed) predicts survival rates and dementia and slower gait speed at baseline predicts depressive symptoms. ${ }^{14}$ Likewise, using the actigraphy method, the differences in motor activity may constitute a potential biomarker for individuals with mood disorders. Undoubtedly, the cognitive and motor aspects of everyday life share behavioral and etiological factors that can inform (the best) treatment selection for individual patients.

Yet, regardless of the complexity of the circular causality between different specific, but interconnected, levels of analysis (genomics, muscular coordination, executive functions, brain activity...), it does not define any ontological effect of a specific level on other levels in terms of understanding the mechanisms by which the mental health problems and life trajectories evolve, stabilize, and update. The assumption stated here is that our quality of life is closely linked to our sensorimotor present. The French philosopher Henri Bergson ${ }^{15}$ has already been aware that "The psychical state, then, that I call 'my present', must be both a perception of the immediate past and a determination of the immediate future. Now the immediate past, in so far as it is perceived, is, as we shall see, sensation, since every sensation translates a very long succession of elementary vibrations; and the immediate future, in so far as it is being determined, is action or movement. My present, then, is both sensation and movement; and, since my present forms an undivided whole, then the movement must be linked with the sensation, must prolong it in action. Whence I conclude that my present consists in a joint system of sensations and movements" ( $(177)$.

Each posture, each step, and each movement results from controlled and automatic human information processing and from the activity of spinal and corticospinal pathways that control balance, gait, or fine motor coordination. Mechanistically, brain networks that control movement overlap with networks involved in cognitive performance and most psychiatric disorders. Thus embracing how embodied neuronal movements of us as social beings fall within our daily executive functioning activities will certainly enhance our understanding of psychiatric disorders that are by definition complex and heterogeneous.

To cite a final example, major depressive disorder is associated with both motor and cognitive impairments, as reflected in the reduction of gait speed or balance stability assessed under cognitively demanding conditions (i.e. dual-task). By exploring the heuristic aspect of motor function in major depression, the posture-cognitive dual tasking performance has been shown to be a solid hallmark of depression-related psychomotor retardation. ${ }^{4}$ Interestingly, the initial postural instability-based on the analysis of center-of-pressure trajectories recorded by a force platform-is likely a sound moderator of positive outcomes in depressed patients after a repetitive transcranial magnetic stimulation intervention, as evidenced by significant improvements in the psychomotor retardation symptom, depression symptoms and postural control.

Reasonably, this "movement" for clinical and basic research in psychiatry should implicate basic motor assessments (e.g. dual-task gait/balance tests) as standard practice in the care of patients with mood disorders. Beyond the feasibility of implementing earlier detection, intervention and assessment of cognitive-motor disorders for these specific populations, the interest might be clinically crucial. For harnessing a "big movement data" to improve diagnosis and personalized treatments.

Is psychiatry ready to move? Of course it is. Some relevant research gaps pertaining to the interaction between everyday movements or physical activity and mood disorders are now better identified. However, nothing is more deceptive than obviousness; thus, robust knowledge based on research evidence is still required.

\section{REFERENCES}

1. Cohen BM. Embracing complexity in psychiatric diagnosis, treatment, and research. JAMA Psychiatry 2016;73:1211-1212.

2. Arbuckle MR, Travis MJ, Ross DA. Integrating a neuroscience perspective into clinical psychiatry today. JAMA Psychiatry 2017;74:313314.

3. Morrison S, Newell KM. Dimension and complexity in human movement and posture. Nonlinear Dynamics Psychol Life Sci 2015;19:395418.

4. Deschamps T, Sauvaget A, Pichot A, Valrivière P, Maroulidès M, Bois A, et al. Posture-cognitive dual-tasking: a relevant marker of depression-related psychomotor retardation. An illustration of the positive impact of repetitive transcranial magnetic stimulation in patients with major depressive disorder. J Psychiatr Res 2016;83:86-93.

5. Lohr JB, May T, Caligiuri MP. Quantitative assessment of motor abnormalities in untreated patients with major depressive disorder. J Affect Disord 2013;146:84-90.

6. Reijnders JSAM, Ehrt U, Weber WEJ, Aarsland D, Leentjens AF. A systematic review of prevalence studies of depression in Parkinson's disease. Mov Disord 2008;23:183-189. 
7. Radovanović S, Jovičić M, Marić NP, Kostić V. Gait characteristics in patients with major depression performing cognitive and motor tasks while walking. Psychiatry Res 2014;217:39-46.

8. Schuch FB, Deslandes AC, Stubbs B, Gosmann NP, Silva CTB da, Fleck MP de A. Neurobiological effects of exercise on major depressive disorder: a systematic review. Neurosci Biobehav Rev 2016;61:1-11.

9. Dunn AL, Trivedi MH, Kampert JB, Clark CG, Chambliss HO. Exercise treatment for depression: efficacy and dose response. Am J Prev Med 2005;28:1-8.

10. Biddle S. Physical activity and mental health: evidence is growing. World Psychiatry 2016;15:176-177.

11. Eyre HA, Papps E, Baune BT. Treating depression and depression-like behavior with physical activity: an immune perspective. Front Psychia- try 2013;4:3.

12. Loprinzi PD, Herod SM, Cardinal BJ, Noakes TD. Physical activity and the brain: a review of this dynamic, bi-directional relationship. Brain Res 2013;1539:95-104

13. Wallace ML, Frank E, Kraemer HC. A novel approach for developing and interpreting treatment moderator profiles in randomized clinical trials. JAMA Psychiatry 2013;70:1241-1247.

14. Sanders JB, Bremmer MA, Deeg DJ, Beekman AT. Do depressive symptoms and gait speed impairment predict each other's incidence? A 16-year prospective study in the community. J Am Geriatr Soc 2012; 60:1673-1680.

15. Bergson H. Matter and Memory. New York: Zone Books; 1988. 